\title{
A study on Antitumor Effect of 1, 2, 4-Thiadiazole Derivatives in Liver and Breast Cancer Cell Lines Hep G2 by Using (HCS) Technique
}

\author{
Sarah A. Mahdi \\ Department of Chemistry, College of Science, Al-Nahrain University, Baghdad-Iraq. \\ Corresponding Author: sarah_abdalaader@yahoo.com.
}

\begin{abstract}
Multi-parametric investigation of composite poisoning at the level of specific cells, by using cellular and pour cytometry showing constructed tactics for example high-content screening, play key roles to find the poisoning and arrangement of components deepened on notice forms reversible and irreversible cellular disadvantage. To probe the effect of 1,2,4-triazole derivative cultured cellular model (liver carcinoma cell line) using HCS, this work was achieved. By an induction of apoptosis, with cells then was tested by Annexing V spotting and cell decrease as demonstrated .The products indicated that the derivative lead in the disturbance of membrane mitochondrial potential (MMP), cell tissue perviousness, nuclear abbreviation, shatter and freedom for cytochrome $\mathrm{c}$ of the mitochondrial addicted on cytosol. This finding suggests that derivative is a potential liver carcinoma inhibitor matched to doxorubicin as affirmative control. Also the data indicated that 1,2,4-triazole derivative possibly will have therapeutic importance in liver cancer treatment which value more development. [DOI: $10.22401 /$ JNUS.20.4.05]
\end{abstract}

Keywords: Tumor, Multiple Cytotoxicity Assay (HCS), Mitochondrial membrane permeability, Cytochrome c, nuclear intensity.

\section{Introduction}

Tumor is a complex inborn malady that is caused first and foremost by ecological reasons. The cancer-causing agents can be existent in food, water, air, chemicals and sunlight that general public are exposed to $[1,2]$. Any chemical that cause a change in the DNA sequence is called a mutagen, mutagens are also carcinogens (cancer-causing chemicals), most cancers result from mutation in a single normal cell, and mutation also can arise from mistakes made by DNA polymerase during DNA replication [3]. The second stage is the metastasize of cancer cells to the other organs of body making difficult to deal with one cell begin to grow elsewhere in the body $[4,5]$. Kundson etal. [6] studied cellular growth and division are controlled by biochemical pathways using signals from inside and outside the cell, disrupted control can be caused by genetic alterations of growth controlling genes, viral infection, increased stimulation by growth factors, or a combination of these factors .To improve the medicine innovation and improvement method, high Content Screening (HCS) knowledge propositions a major occasion. HCS allows the assessment of multiple biochemical and morphological parameters in cellular systems and enables description of the subcellular distribution of fluorescent motions with labeled components. By linking the programmed imaging of cells in micro titer plates with certified finding reagents and potent image analysis algorithms, scientists can presently get bottomless knowledge of multiple morphological or biochemical passageways on the single-cell level, commonly in a lone test, at an first step in the expansion of new drugs [7].

\section{Materials and Methods}

The synthesized of [4-(N,N- dimethyl)-3(3-Mercapto-5- Phenyl[1,2,4] triazol-4yl)thiazolidin-4-one] was derived permitting to Ayah [6], as given away in structure below. 

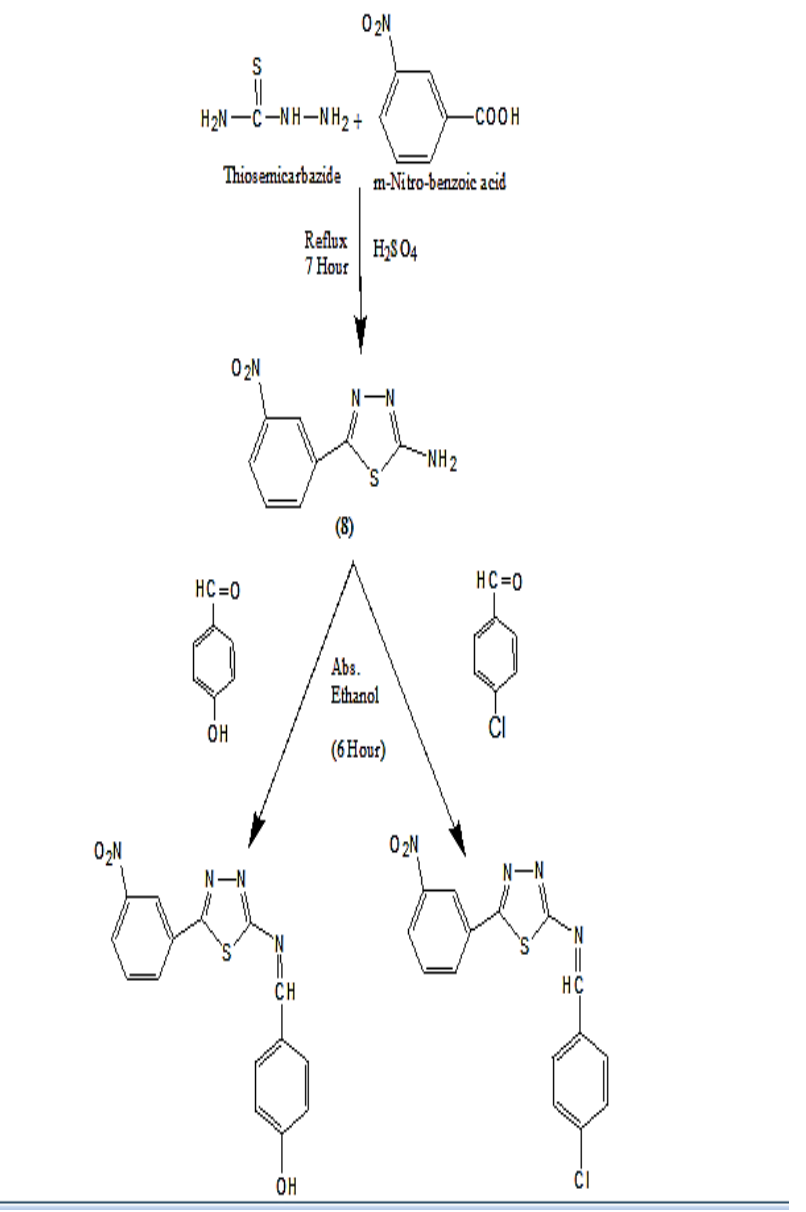

Structure (1): Steps for production of composites (1-L).

\subsection{Multiplier Cytotoxicity Assay (HCS)}

To described Cellomics Multi-parameter Cytotoxicity by use three Kit. This kit allows concurrent measurement in a like cell of six autonomous parameter which observer heath cell, as well as cell cost [8], fissile volume, and formalism_modifications, MMP variations, cytochrome (c) relief, and variation in cell tissue perviousness. Concisely, twenty four hours afterward $\mathrm{AuL}_{2}$ therapy, MMP color and cell porousness pigmentation were supplemented at animate cells that nurtured for thirty minutes at thirty-seven ${ }^{\circ} \mathrm{C}$. Cells were stable, perviousness, and choked with (1X) blocking out bumper previously penetrating with main cytochrome (c) prime anti-body and ancillary Dylight (649) conjugate goat antimouse (IgG) for one hour each one. Hoechst (33342) was supplemented in the discoloration solutions to tint the nucleus. Paten with tainted cells, were studied by Arrays test high content screening method (Cellomics, PA., USA). The Arrays Scan (HCS) method is automate programmed fluorescence image microscope that spontaneously detects tainted cells, and informations the strength and giving through fluorescence in singular cells. Each one fully, 1,000 cells were examined. photo were obtained for every single fluorescence station by using appropriate filters. Data and Images on texture and intensity of the fluorescence in every cell, and middling fluorescence for the cell people contained by the fully, were amassed in a Microsoft (SQL) data base for to ease recovery. Records were taken, extracted and studied by use Array Scan (II) Data conquest and Information version viewer 3.0 (Cellomics) [9].

\section{Results and Discussion}

\subsection{In height content screening and exploration}

Cytotoxic results of cell-composite interactions were estimated by (HCSA) in one cellular model (Hep G2 cell) afterward twenty four acquaintances. The estimation of the (HCSA) images of acquired (Diagram 1), listed the cytotoxic reply into $\mathrm{AuL}_{2}$ was dosebased on. The multi-parametric analysis on condition that quantitatively information on the modifications within five regularly used cellular parameters [10], as well as cell existence, tissue perviousness, mitochondria tissue perviousness, cytochrome (c), and nuclear strength.

\subsubsection{Cell tissue permeability}

Cell tissue perviousness is every so often linked with ongoing lethal or apoptotic reply, and injury of tissue cell honesty is a common phenotypically feature of clear cytotoxicity [11]. This element was used as main parameters to appraise for cell-composite interact. A significantly growth in cell tissue perviousness (appraised by the greenfluorescence emission) that recorded Diagram (1). Perviousness tint blemished intensely in $(200 \mu \mathrm{g} / \mathrm{mliter}) \mathrm{AuL}_{2}$ - treated cells paralleled to doxorubicin-treated cells in $(20 \mu \mathrm{g} / \mathrm{mliter})$. The dose-based on augmentation in cell tissue Perviousness was noteworthy $77.8 \%$ compared to Doxorubicin in $(200 \mu \mathrm{g} / \mathrm{mliter})$ Diagram (1). 


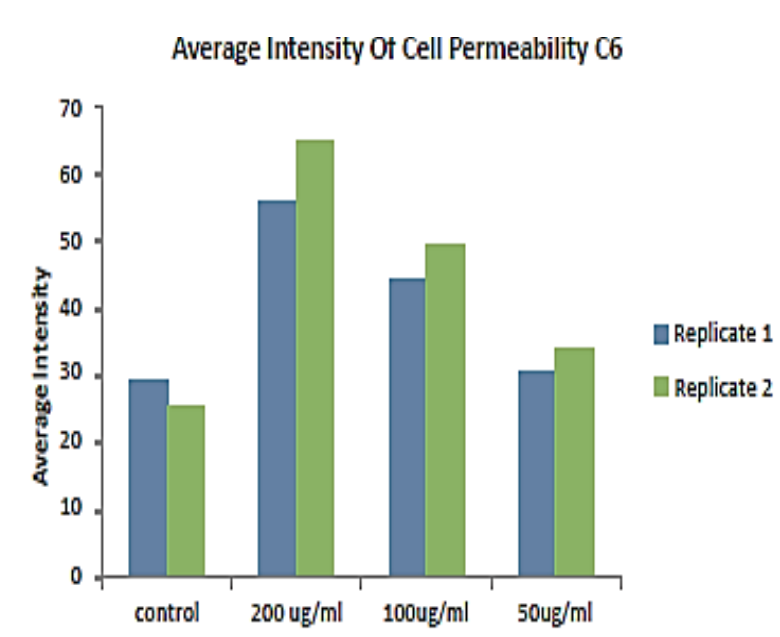

Average Intensity of Cell Permeability Doxorubicin

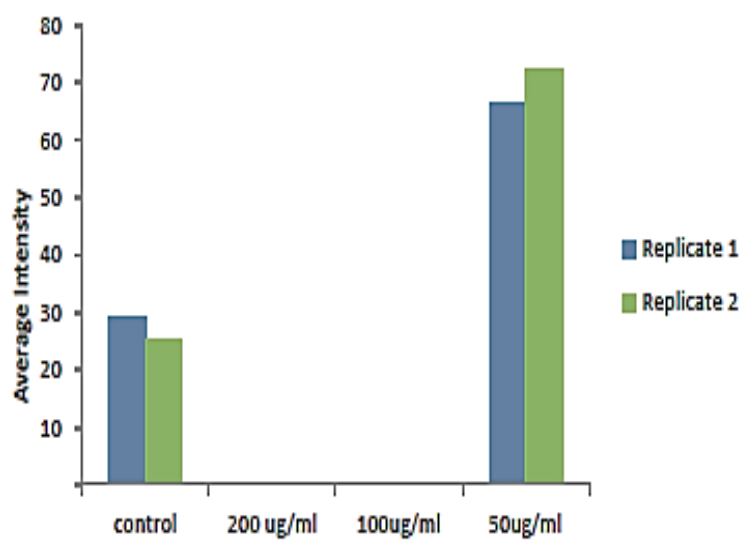

Diagram (1): Dose-based on increase of cell tissue Perviousness compared to $50 \mu \mathrm{g} / \mathrm{ml}$ doxorubicin give control positive (+) regulator and un-treated tumor cell give control negative(-).

\subsubsection{Mitochondrial tissue permeability}

To good description the cell loss signing proceedings in complex poisoning, the upshot from complex on modifications in tissue of mitochondrial Perviousness was examined. Variations in the trans mitochondrial tissue potency in Hep G2 cells, treat with compound, so measured by drift cytometry with Mitochondrial overlay Potential Dye (MMP). Treating with $50 \sim 200 \mu \mathrm{g} / \mathrm{mliter}$ of $1,2,4-$ Triazole for $24 \mathrm{~h}$ greater than before the proportion of Hep G2 cells with de-polarized mitochondria (considered small prices of trans tissue potency) (Diagram 2-A). Accordingly a mitochondria-arbitrated cell demise signaling event, slit the mitochondrial Perviousness pore alteration caused a relief of c cytochrome from the mitochondria at the cytosol $[12,13]$. MMP tint blemished powerfully and diffusely in cyto-plasm of controller cells paralleled to
$200 \mu \mathrm{g} / \mathrm{mliter} \quad$ composite-treat cells (Diagram 2-B).



Diagram 2-A

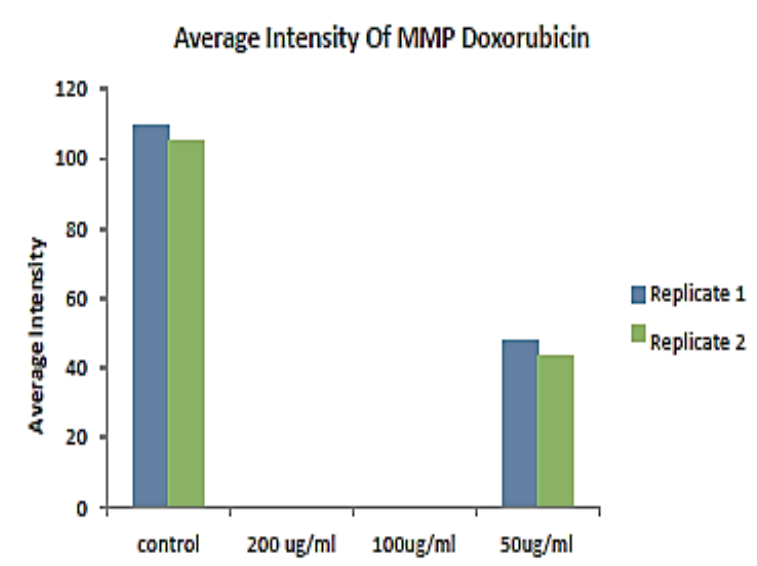

Diagram 2-B

Diagram( 2-A, 2-B): Dose-based on lessened mitochondrial tissue Perviousness compare to $50 \mu \mathrm{g} / \mathrm{mliter}$ doxorubicin as positive( + ) regulator and un-treated tumor cell as negative (-).

\subsubsection{Intensity for Nuclear}

Nuclear Condensation and shatter are hallmarks of apoptosis. Morphological of nuclear change of Hep G2 breast tumor cells was examined by smearing the cells with Hoechst 33342. The results appear that some treated-cells display nuclear intensification and fragmentation twenty four hours after gold (III) complex treatment. Intensity of nuclear, identical to apoptotic changes, significantly decreased following gold(III) complex treatme in breast tumor cells[14,15] Digram (3). 


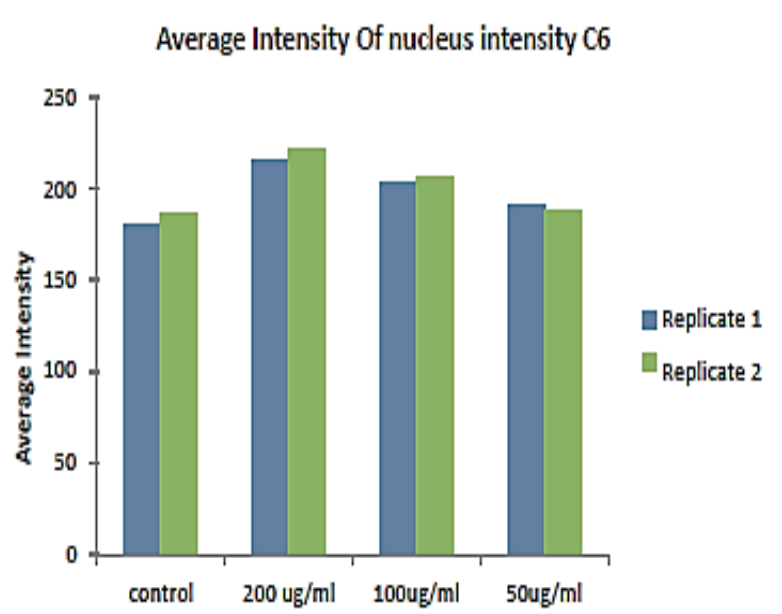

\section{Diagram (3): Dose-based on lessening for nuclear strength contrast to $50 \mu \mathrm{g} / \mathrm{mliter}$ doxorubicin as positive(+) regulator and un- treated tumor cell as negative(-) regulator.}

\section{Conclusion}

A number of cellular parameters (e.g., tissue Perviousness, mitochondria tissue Perviousness, and nuclear strength) were measured by the use of the HCSA method. Commencing the united quantitatively HCSA analyses at twenty four hours exposition for triazole composite, these results suggest that 1,2,4-triazole might cause cell doom in MCF 7 cells by inducing a mitochondrial tissue Perviousness alteration, which lead to $\mathrm{c}$ cytochrome discharge and apoptotic cell loss.

\section{References}

[1] Fan X., Khaki L., Zhu T.S., Soules M.E., Talsma C.E., Gul N., Koh C., Zhang J., Li Y.M., Maciaczyk J., Nikkhah G., Dimeco F., Piccirillo S., Vescovi A.L., Eberhart C.G., Notch pathway blockade depletes CD133-positive glioblastoma cells and inhibits growth of tumor neurospheres and xenografts, Stem Cells 28(1), 5-16, 2010.

[2] Li J., Chen L., Goyal B., Laidig G., Stanton T.F., Sjogren E.B., inventors; Calithera Biosciences I., assignee, Heterocyclic inhibitors of glutaminase, United States patent US 8604016. 10, 2013.

[3] Denniston K.J., Topping J.J., Caret R.L., General organic and biochemistry MC Graw-Hill edition(4) ${ }^{\text {th }}, 2004$.

[4] Hassan F., Mohammed G., Mahdi S., Mahdy S., Win. Y, Mohammed S., Yousif E., Cytochrome P450s in Breast Cancer,
Research Journal of Pharmaceutical, Biological and Chemical Sciences 7(5), 243-251, 2016.

[5] Barretina J., Caponigro G., Stransky N., Venkatesan K., Margolin A. A., Kim S., The cancer cell line encyclopedia enables predictive modelling of anticancer drug sensitivity, Nature 7, 483-603, 2012.

[6] H Ayah, H Firas, Synthesis, Characterization and Antioxidant Activity of Some 4-Amino-5-Phenyl-4h-1, 2, 4Triazole-3-Thiol Derivatives, International Journal of Applied Science and Technology 4 (2), 202-211, 2014.

[7] Giuliano K.A., Cheung W. S., Curran D. P., Systems cell biology knowledge created from high content screening, ASSAY and drug dev. tech. 3, 501-514, 2005.

[8] Hassan F., Elhiti G.A., Abd Allateef M., Yousif E., Cytotoxicity anticancer activities of anastrozole against breast, hepatocellular, and prostate cancer cells Saudi medical journal 38(4), 359-365, 2017.

[9] Byrne F., Prina-Mello A., Whelan A., Mohamed B.M., Davies A., Gun'ko Y.K., Coey J.M.D., Volkov Y., High content analysis of the biocompatibility of nickel nanowires, Magn. Magn, J. Mater., 321, 1341-1345, 2009.

[10] George S., Pokhrel S., Xia T., Gilbert B., Ji Z.X., Schowalter M., Rosenauer A., Damoiseaux R., Bradley K. A., Madler L., Nel A. E. et al., Use of a rapid cytotoxicity screening approach to engineer a safer zinc oxide nanoparticle through iron doping, ACS Nano 4,15-29, 2010.

[11] Abraham V. C., Towne D.L., Waring J.E., Warrior U., Burns D.J., Application of a high-content multiparameter cytotoxicity assay to prioritize compounds based on toxicity potential in humans. J. Biomol. Screening 13, 527-537, 2008.

[12] Czerski L., Nũnez G., Apoptosome formation and caspase activation, is it different in the heart,. Journal of Molecular and Cellular Cardiology 37(3), 643-652, 2004. 
[13] Massimo Bonora1 and Paolo Pinton1., The mitochondrial permeability transition pore and cancer: molecular mechanisms involved in cell death, doi: 10.3389/fonc.2014.00302. 4(17),302, 2014.

[14] Kim R., Emi M., Tanabe K., Role of mitochondria as the gardens of cell death. Cancer Chemother Pharmacol 57, 545-553, 2006.

[15] Jihyoun Lee, Dev Kumar Chatterjee, Min HyukLee, SunilKrishnan, Gold nanoparticles in breast cancer treatment, Promise and potential pitfalls, https://doi.org/10.1016/j.canlet.2014.02.006 V 347(1), 46-53, 2014. 